\title{
KAJIAN DATABASE RELASIONAL DAN NONRELASIONAL PADA DATA BPS DALAM MENGHADAPI ERA BIG DATA
}

\author{
(Relational and Nonrelational Database Study on BPS-Statistics Indonesia Data in Facing \\ Era of Big Data)
}

\author{
Muhammad Arif Rahman', Lutfi Rahmatuti Maghfiroh² \\ Politeknik Statistika STIS \\ E-mail: fourth197@gmail.com
}

\begin{abstract}
ABSTRAK
Big data merupakan tantangan yang perlu dihadapi kedepannya, terutama bagi BPS sebagai badan penyedia data sensus dan survei. Teknologi penyimpanan data seperti MySQL, PostgreSQL, dan lainnya yang merupakan penyimpanan berbasis relasional mempunyai batasan-batasan dalam menghadapi era big data. Untuk mengatasi batasan-batasan yang ada tersebut, kemudian berkembanglah teknologi penyimpanan data berbasis nonrelasional yang dikenal dengan istilah NoSQL Database. Hingga saat ini telah banyak teknologi nonrelational database yang berkembang, contohnya Hadoop dan Couchbase. Perlunya penentuan teknologi penyimpanan data yang sesuai merupakan salah satu faktor penting dalam menghadapi era big data agar dapat memberikan performa kinerja yang maksimal. Atas dasar tersebut, penulis melakukan penelitian dengan mengkaji beberapa sistem database terpilih sebagai alternatif dalam menghadapi era big data. Penelitian dilakukan dengan membandingkan tiga teknologi database yaitu Hadoop, Couchbase, dan MySQL untuk melihat perbedaan performa dari ketiga database tersebut dalam penerapannya terhadap data Sensus/Survei BPS. Dari hasil penelitian menggunakan data individu SUSENAS, diperoleh hasil yaitu setiap database mempunyai keunggulan dan kelemahan masing-masing baik dari segi performa maupun fitur yang diberikan. MySQL memiliki keunggulan pada operasi write dengan multiple insert, Couchbase memiliki keunggulan pada operasi write dengan single insert, sedangkan Hadoop lebih unggul pada operasi read.
\end{abstract}

Kata kunci: relational database, MySQL, nonrelational database, Hadoop, Couchbase

\section{ABSTRACT}

Big data is a challenge that needs to be faced in the future, especially for BPS-Statistics Indoenesia as a census and survey data provider department. Data storage technologies such as MySQL, PostgreSQL, and others which are relational based storage have limitations in dealing with the era of big data. To overcome these limitations, then nonrelational based data storage technology developed known as NoSQL Database. Until now many nonrelational database technologies have been developed, for example Hadoop and Couchbase. The need to determine the appropriate data storage technology is one important factor in dealing with the era of big data in order to provide maximum performance. On this basis, the authors conducted research by examining a number of selected database systems as alternatives in dealing with the era of big data. The study was conducted by comparing three database technologies namely Hadoop, Couchbase, and MYSQL to see differences in the performance of the three databases in their application to BPS-Statistics Indonesia Census / Survey data. From the results of the study using SUSENAS individual data, the results obtained are that each database has advantages and disadvantages of each in terms of performance and features provided. MYSQL has the advantage of write operations with multiple inserts, Couchbase has the advantage of write operations with a single insert, while Hadoop is superior to read operations.

Keywords: relational database, MySQL, nonrelational database, Hadoop, Couchbase

\section{PENDAHULUAN}

Big Data merupakan istilah yang pada awalnya digunakan untuk menggambarkan data dengan ukuran yang sangat besar. Hingga saat ini istilah Big Data telah banyak berkembang dan mempunyai makna yang sangat luas, namun definisi yang paling terkenal adalah karakteristik 3V (volume, velocity, variety) (Kapil, 2016) yang digunakan untuk menggambarkan karakteristik dari Big Data. Big Data menjadi suatu tantangan yang masih terus dikaji hingga saat ini. Teknologi penyimpanan data seperti MySQL, PostgreSQL, dan lainnya yang merupakan database berbasis relasional mempunyai batasan-batasan dalam menghadapi Big Data (Leavitt, 2010). Untuk mengatasi batasanbatasan yang ada tersebut, kemudian berkembanglah teknologi penyimpanan data nonrelasional 
yang dikenal dengan istilah NoSQL Database (Vohra, 2015). Hingga saat ini telah banyak teknologi penyimpanan data nonrelasional yang sudah berkembang, contohnya Hadoop dan Couchbase.

Setiap database nonrelasional yang ada hingga saat ini dikembangkan sesuai dengan permasalahan, kebutuhan dan keperluan dari setiap pengembang maupun organisasi. Big Data merupakan tantangan yang perlu dihadapi kedepannya, terutama bagi BPS sebagai badan penyedia data sensus dan survei. Perlunya penentuan teknologi yang tepat dalam menghadapi era Big Data sangat penting agar dapat memberikan kinerja dan performa yang maksimal. Di BPS sendiri, penerapan teknologi database nonrelasional tergolong masih sangat minim, dimana masih dalam proses pengkajian penerapan Hadoop untuk data lake data-data survey dan sensus BPS. Selain itu, teknologi nonrelational database yang dikaji hanya terbatas pada Hadoop, sedangkan hingga saat ini telah banyak berkembang teknologi database nonrelasional yang mungkin saja lebih cocok jika diterapkan pada data-data BPS.

Penelitian yang sudah dilakukan antara lain dilakukan oleh Li dan Sathiamoorthy (2013) dalam tulisannya yang berjudul "A performance comparison of SQL and NoSQL databases" melakukan perbandingan perrforma beberapa nonrelational database dan relational database diantaranya MongoDB, CouchDB, Couchbase, RavenDB, Cassandra, Hypertabe, dan SQL Express. Performa yang dibandingkan terdiri dari 4 operasi mendasar, yaitu Instantiate, Read, Write, dan Delete. Uji coba dilakukan pada dataset dengan data bangkitan berupa pasangan key-value sebanyak 100000 records. Hasil dari uji coba tesebut, RavenDB dan CouchDB tidak menghasilkan performa yang cukup baik dalam hal operasi read, write dan delete. Cassandra menghasilkan performa yang lambat dalam hal operasi read, namun cukup baik pada operasi write dan delete. Couchbase dan MongoDB merupakan dua database yang tercepat dalam hal operasi read, write, dan delete.

Tang dan Yushun (2016) dalam tulisannya yang berjudul "Performance comparison between five NoSQL databases" melakukan perbandingan terhadap 5 nonrelational database yaitu Redis, MongoDB, Couchbase, Cassandra, dan HBase. Dalam penelitiannya, Tang dan Yushun menggunakan YCSB (Yahoo! Cloud Serving Benchmark) sebagai framework untuk membandingkan performa database. Chopade dan Nikhil (2017) dalam tulisannya yang berjudul "MongoDB, Couchbase: performance comparison for image dataset" melakukan perbandingan antara 2 document database yaitu MongoDB dan Couchbase dengan membandingkan performa operasi insert dan retrieve pada dataset berupa gambar.

Atas dasar tersebut, peneliti melakukan penelitian dengan mengkaji beberapa teknologi penyimpanan data terpilih sebagai alternatif dalam menghadapi era Big Data. Penelitian yang dilakukan bertujuan untuk mengkaji dan menganalisis penerapan teknologi database nonrelasional untuk peningkatan performa penyimpanan data BPS dalam menghadapi era big data.

\section{METODE}

Penelitian dilakukan dengan melakukan simulasi untuk melihat performa dari ketiga database terpilih, yaitu teknologi nonrelational database document oriented dengan menggunakan Couchbase, Hadoop, dan teknologi relational database dengan menggunakan MySQL. Document oriented dipilih karena mampu menyimpan data dalam bentuk objek berupa dokumen dengan format JSON maupun XML sehingga dapat mengatasi data-data dengan struktur yang berbeda-beda pada setiap survei dan sensus di BPS.

Document oriented database yang dipilih untuk digunakan dalam rancangan penelitian yaitu Couchbase. Couchbase mempunyai fitur N1QL yang memungkinkan untuk melakukakn query seperti layaknya SQL terhadap dokumen dengan format JSON, fitur N1QL dapat memudahkan pengguna yang terbiasa dengan SQL untuk dapat menggunakan Couchbase sebagai salah satu opsi nonrelational database. Selain itu, fitur-fitur unik lainnya yang hanya dimiliki Couchbase seperti yang dijabarkan pada landasan teori menjadi daya tarik peneliti untuk menggunakan Couchbase dalam rancangan penelitian.

2 database lain yang digunakan dalam rancangan penelitian yaitu Hadoop dan MySQL. Hadoop dimasukkan dalam rancangan penelitian karena merupakan teknologi database yang sedang dikaji di BPS untuk diterapkan sebagai Data Lake, sedangkan MySQL dimasukkan dalam rancangan penelitian karena merupakan teknologi relational database yang paling umum dan banyak digunakan di BPS. Dalam rancangan penelitian, performa kinerja yang dibandingkan antara ketiga jenis 
database hanya difokuskan pada operasi read-write. Pertimbangan yang menjadi dasar kenapa operasi database yang diuji hanya terbatas pada operasi read-write adalah karena data yang disimpan secara permanen di penyimpanan database BPS merupakan data yang sudah bersih sehingga sangat jarang dilakukan update-delete pada data final yang telah masuk ke database.

Perangkat keras yang digunakan untuk melakukan percobaan yaitu satu buah laptop dengan spesifikasi processor intel core i5-4300M CPU @2.60GHz (4CPUs), RAM DDR3L 16GB (dual channel), memory HDD 500GB. Pada environment tersebut dilakukan instalasi beberapa perangkat lunak yang dijalankan pada sistem operasi Ubuntu 18.04.2 LTS 64-bit. Untuk keperluan hadoop dilakukan instalasi Java 1.8, Hadoop 3.2.0, Hbase 2.2.0, Hive 3.1.1. Untuk Couchbase digunakan Couchbase 6.0.1 dan untuk MySQL digunakan MySQL 8.0. Selain itu, dilakukan instalasi Apache2 sebagai web server dan PHP 7.2 sebagai bahasa script yang digunakan.

Data yang digunakan dalam percobaan yaitu data SUSENAS periode maret 2017 yang bersumber dari BPS. Data SUSENAS dipilih karena merupakan salah satu data strategis BPS dengan struktur dan ukuran data yang cukup besar. Data individu SUSENAS maret 2017 yang digunakan terdiri dari 1132749 record dan 255 variabel ditambah dengan 1 variabel bangkitan sebagai variabel unik sehingga jumlah variabel total menjadi 256 variabel. Karena keterbatasan dalam memperoleh data, data yang digunakan hanya terbatas pada 1 periode waktu yaitu data Maret 2017.

Tabel 1. Query statement operasi read.

\begin{tabular}{cl}
\hline Jenis Query & Query Statement \\
\hline Q1 & SELECT * FROM susenasmaret17.kor17art; \\
\hline Q2 & SELECT * FROM susenasmaret17.kor17art WHERE R101 LIKE '6\%'; \\
\hline Q3 & SELECT * FROM susenasmaret17.kor17art WHERE R407 > 15 AND R511 = 5 AND R512 = 5 \\
& AND R513 = 5; \\
\hline Q4 & SELECT * FROM susenasmaret17.kor17art WHERE R407 > 15 AND R511 = 5 AND R512 = 5 \\
& AND R513 = 5 GROUP BY R101; \\
\hline Q5 & SELECT col1.*, col2.SD, col3.SMP, col4.SMA, col5.Univ, col6.SedangSekolah, \\
& col7.PutusSekolah \\
& FROM (SELECT R101 AS PROV_ID, COUNT(DOCKEY) AS TidakSekolah FROM \\
susenasmaret17.kor17art WHERE R407 > 5 AND R514 = 1 GROUP BY R101) AS col1 \\
JOIN (SELECT R101 AS PROV_ID, COUNT(DOCKEY) AS SD FROM susenasmaret17.kor17art \\
WHERE R407 > 5 AND R514 = 2 AND R515 IN (1,2,3,4) GROUP BY R101) AS col2 ON \\
col1.PROV_ID = col2.PROV_ID \\
JOIN (SELECT R101 AS PROV_ID, COUNT(DOCKEY) AS SMP FROM \\
Susenasmaret17.kor17art WHERE R407 > 5 AND R514 = 2 AND R515 IN (5,6,7,8) \\
GROUP BY R101) AS col3 ON col1.PROV_ID = col3.PROV_ID \\
JOIN (SELECT R101 AS PROV_ID, COUNT(DOCKEY) AS SMA FROM \\
Susenasmaret17.kor17art WHERE R407 > 5 AND R514 = 2 AND R515 IN \\
(9,10,11,12,13,14) GROUP BY R101) AS col4 ON col1.PROV_ID = col4.PROV_ID \\
JOIN (SELECT R101 AS PROV_ID, COUNT(DOCKEY) AS Univ FROM \\
Susenasmaret17.kor17art WHERE R407 > 5 AND R514 = 2 AND R515 IN \\
(15,16,17,18,19,20) GROUP BY R101) AS col5 ON col1.PROV_ID = col5.PROV_ID \\
JOIN (SELECT R101 AS PROV_ID, COUNT(DOCKEY) AS SedangSekolah FROM \\
Susenasmaret17.kor17art WHERE R407 > 5 AND R514 = 2 GROUP BY R101) AS col6 \\
ON col1.PROV_ID = col6.PROV_ID \\
JOIN (SELECT R101 AS PROV_ID, COUNT(DOCKEY) AS PutusSekolah FROM \\
susenasmaret17.kor17art WHERE R407 > 5 AND R514 = 3 GROUP BY R101) AS col7 \\
ON col1.PROV_ID = col7.PROV_ID;
\end{tabular}

Analisis dilakukan dengan mengevaluasi performa query dari ketiga database yaitu Couchbase, Hadoop, dan MySQL yang dilihat dari segi lama waktu eksekusi dalam melakukan operasi read-write. Pada operasi write, query dijalankan dengan mengubah jumlah data yang di insert pada setiap query, yaitu mulai dari 10000, 20000, 30000, 40000, 50000, 75000, 100000, 125000, 150000, 200000, 250000, 300000 dan 400000 records. Selain itu, operasi write juga dilakukan dengan dua cara yaitu single insert dengan memasukkan record satu per satu ke dalam database hingga mencapai jumlah yang ditentukan kemudian diperoleh lama waktunya dan multiple insert dengan memasukkan sejumlah records secara langsung dalam database. 
Pada operasi read dilakukan 5 jenis query yang berbeda mulai dari query sederhana hingga query yang lebih kompleks. Query statement yang digunakan ditunjukkan pada Tabel 1. Query 1 melakukan pengambilan seluruh data yang tersimpan. Query 2 melakukan pengambilan seluruh data di pulau kalimantan. Query 3 melakukan pengambilan data penduduk yang tidak bisa baca tulis (buta huruf). Query 4 melakukan pengambilan data jumlah penduduk yang tidak bisa baca tulis (buta huruf) berdasarkan provinsi. Query 5 melakukan pengambilan data pendidikan penduduk usia lebih dari 5 tahun yang dikelompokkan berdasarkan provinsi. Setiap operasi dicatat lama waktu eksekusinya dengan menggunakan PHP script dengan fungsi microtime() sebelum dan sesudah query dijalankan, dan diperoleh hasil selisihnya sebagai lama waktu eksekusi yang diperlukan.

\section{HASIL DAN PEMBAHASAN}
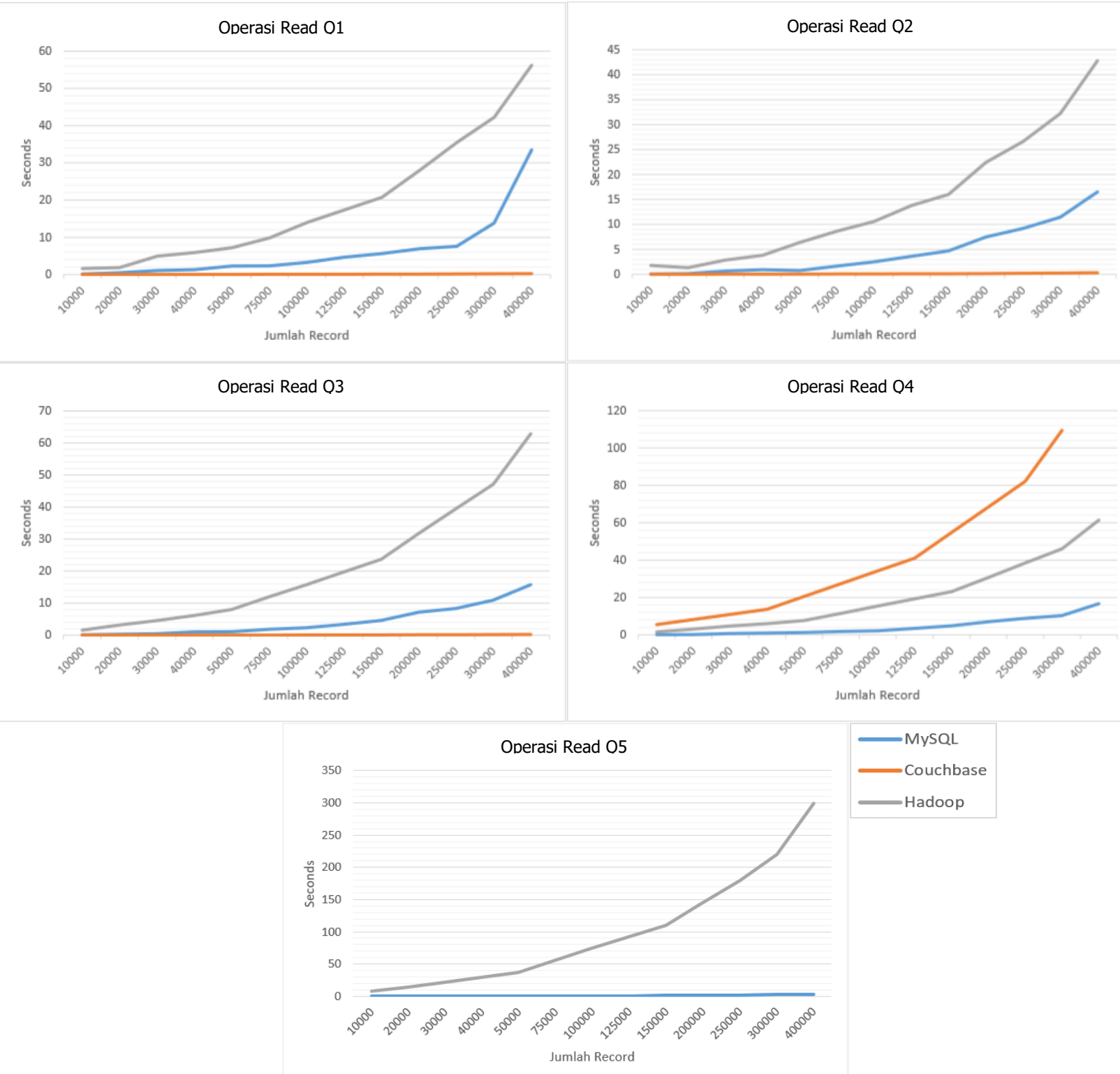

Gambar 1. Perbandingan hasil ujicoba operasi read dengan 5 jenis query

Gambar 1 menunjukkan hasil percobaan operasi read dengan 5 jenis query (Tabel 1). Terlihat bahwa Hadoop secara signifikan mempunyai kecepatan yang lebih cepat hampir pada setiap jenis query, kecuali pada Q4 dan Q5. Pada Q4 dan Q5, operasi melibatkan fungsi agregat count() sehingga melibatkan proses mapreduce pada hdfs yang menyebabkan peroses lebih lambat. Pada Q5 Couchbase belum mampu untuk melakukan query statement join select karena fungsi join pada Couchbase hanya bisa dilakukan pada bucket yang sudah tersimpan. Setelah Hadoop, performa dari 
MySQL menempati posisi kedua sedangkan Couchbase menghasilkan performa yang paling lambat dibandingkan dua database lainnya.

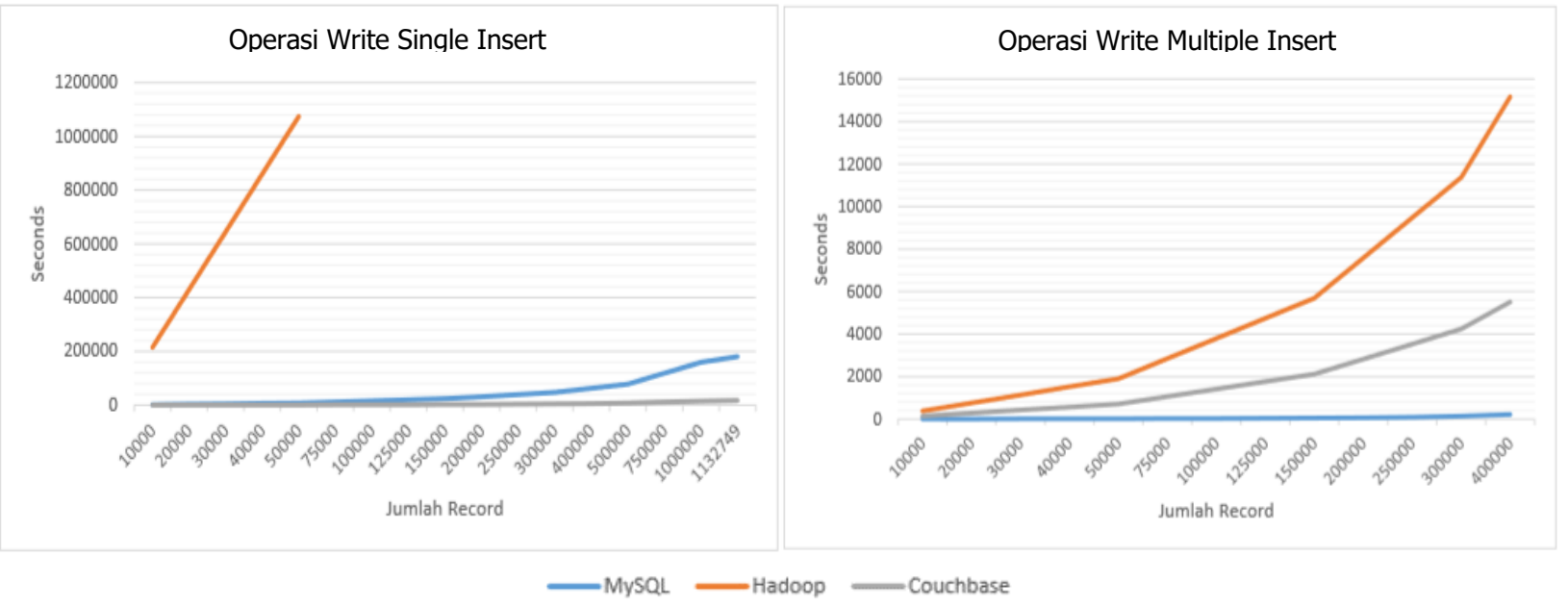

Gambar 2. Perbandingan hasil ujicoba operasi write dengan single insert dan multiple insert

Gambar 2 menunjukkan grafik hasil perbandingan performa dari ketiga database dalam melakukan operasi write. Operasi write yang dibandingkan dilakukan dengan single insert dan multiple insert (bulk insert). Pada operasi single insert, Couchbase dan MySQL menghasilkan performa yang sangat signifikan dibandingkan dengan Hadoop. Meskipun demikian, tetap Couchbase menghasilkan performa yang paling cepat dari operasi write dengan single insert. Hadoop menghasilkan performa paling lambat karena setiap kali query single insert dijalankan, proses mapreduce akan dijalankan yang menyebabkan proses menjadi lambat. Sedangkan pada operasi multiple insert dapat dilihat bahwa MySQL menghasilkan performa yang lebih cepat dibandingkan dengan dua database lainnya. Sedangkan Hadoop menghasilkan performa yang paling lambat karena seperti halnya single insert, query pada multiple insert juga melalui proses mapreduce pada HDFS.

\section{KESIMPULAN}

Pada penelitian ini telah dilakukan kajian terhadap beberapa teknologi nonrelational database yaitu Couchbase dan Hadoop yang dibandingkan dengan teknologi relational database yang diwakili dengan MySQL. Dilihat dari segi fitur dan karakteristik ketiga database, nonrelational database memberikan beberapa keunggulan seperti schema-less yang memungkinkan penyimpanan data tanpa perlu mendefinisikan skema terlebih dahulu dan memberikan kemudahan ketika terjadi perubahan struktur data sehingga mempercepat dalam proses perancangan database maupun ketika terjadi perubahan database yang memerlukan perancangan ulang database.

Selain itu, dengan menggunakan data individu SUSENAS maret 2017 telah dilakukan percobaan dengan melakukan operasi read dan write pada beberapa skenario untuk melihat perbandingan kinerja performa dari ketiga database tersebut. Hasilnya MySQL lebih unggul dalam hal operasi write dengan multiple insert, Couchbase lebih unggul dalam hal operasi write dengan single insert, dan Hadoop lebih unggul dalam hal operasi read.

Penelitian berikutnya dapat dikembangkan dengan melakukan kajian tidak sebatas pada operasi read-write, namun juga fitur lain seperti tingkat keamanan dari sistem database ataupun penerapan arsitektur multi-node. Selain itu, data yang digunakan pada percobaan dapat diperbanyak sehingga tidak terbatas hanya 1 periode agar menambah kompleksitas dan ukuran dari data serta menambahkan skenario percobaan yang disesuaikan dengan kebutuhab subject matter sehingga lebih menggambarkan kondisi sebenarnya.

\section{DAFTAR PUSTAKA}

Chopade, M. R. M. \& N. S. Dhavase. (2017). Mongodb, couchbase: Performance comparison for image dataset. 2017 2nd International Conference for Convergence in Technology (I2CT), 255-258. 
Gupta, A., S. Tyagi, N. Panwar, S. Sachdeva \& U. Saxena. (2017). NoSQL databases: Critical analysis and comparison. 2017 International Conference on Computing and Communication Technologies for Smart Nation (IC3TSN), 293-299.

Kaisler, S., F. Armour, J. A. Espinosa \& W. Money. (2013). Big Data: Issues and Challenges Moving Forward. 2013 46th Hawaii International Conference on System Sciences, 995-1004.

Kapil, G., A. Agrawal \& R. A. Khan. (2016). A study of big data characteristics. 2016 International Conference on Communication and Electronics Systems (ICCES), 1-4.

Leavitt, N. (2010). Will NoSQL Databases Live Up to Their Promise?. Computer, 43 (2), 12-14.

Li, Y. \& S. Manoharan. (2013). A performance comparison of SQL and NoSQL databases. 2013 IEEE Pacific Rim Conference on Communications, Computers and Signal Processing (PACRIM), 15-19.

Liu, Q., Y. Fu, G. Ni \& J. Mei. (2017). Big Data Management Performance Evaluation in Hadoop Ecosystem. 2017 3rd International Conference on Big Data Computing and Communications (BIGCOM), 413-421.

Tang, E. \& Y. Fan. (2016). Performance Comparison between Five NoSQL Databases. 2016 7th International Conference on Cloud Computing and Big Data (CCBD), 105-109.

Vohra, Deepak. (2015). Pro Couchbase Development: A NoSQL Platform for the Enterprise. New York: Apress.

Zafar, R., E. Yafi, M. F. Zuhairi \& H. Dao. (2016). Big Data: The NoSQL and RDBMS review. 2016 International Conference on Information and Communication Technology (ICICTM), 120-126 